\title{
AUDIO BOOKS AS TEACHING MEDIA TO BLIND STUDENTS IN LEARNING EFL
}

\author{
Andi Hamzah Fansury ${ }^{1}$, Nursamsilis Lutfin ${ }^{2}$, Susalti Nur Arsyad ${ }^{3}$ \\ Faculty of Teacher Training and Education, Bosowa University, Makassar, Indonesia
}

\begin{abstract}
The focus of this study on the implementation of audio books as teaching media for blind students in learning English. The purpose of this study was to determine the implementation of audio books as teaching media for blind students in learning English and to find out audio books used in learning EFL. The study was conducted at SLB YAPTI Makassar with a number of samples taken were 20 students conducted randomly. The instruments in this study were tests, observations, and questionnaires. The results of the study show that the implementation of audio books as teaching media for blind students in learning English can help students in the learning process. The implementation of the audio book also increases student motivation in learning because it makes it easier for students to study anywhere and anytime.
\end{abstract}

Keywords: Audio Books; Teaching Media; Blind Students, Leaning, EFL

\section{INTRODUCTION}

All children have right to learn at all stages of their development, and to do so in ways that are appropriate and easily accessible to them. A report on World Statistics (UNESCO, 2000) stated that there were about 130 million primary school children in the world who do not go to school; ninety percent $(90 \%)$ of these children live in Africa. Also, one in ten of the world's population is physically or mentally disabled or has a learning disability. Furthermore, less than 2 percent of disabled children have the opportunity to go to school, and girls have fewer opportunities for schooling than boys. Students who are either visually impaired or blind have major problems in gaining educational or learning opportunities because of discrimination in education on the basis of gender, race, or disability. Illiteracy, which often results from a lack of opportunity, relegates many people to life as second-class citizens and sometimes even as non-persons (Blake, 2003).
Since literacy involves the ability to acquire information and communicate with others, the blind person's literacy skills involve many methods of acquiring, storing, and accessing information, and of communicating one's own ideas, opinions, and needs. Accordingly, teachers and families of blind children must strive to empower them to direct and control their learning, thus giving them an opportunity to move upward in society as full participants.

Students who have a visual impairment are as different as any other group of students. A student with a visual impairment could be low vision or blind, depending on the degree of impairment. It's important that teachers understand the nature and degree of the disability. Most students with visual impairments have had extensive involvement with other professionals, such as ophthalmologists and therapists. These professionals can suggest appropriate accommodation for individual students. All plans for these students should involve 
parents and these professionals, whenever possible.

Most students with visual impairments are capable of attending their local school and can participate in the majority of school activities. The provincial school for the blind (W. Ross MacDonald in Brantford) provides education for blind, visually impaired and deafblind pupils. Programs are tailored to the needs of the individual student and are designed to help him/her learn to live independently in a non-sheltered environment. Special subject areas include music, broad based technology, family studies, physical education, and mobility training. The school also provides outreach support to help school personnel through consultation and the provision of special learning materials, e.g., braille materials, audio tapes, and large-print textbooks.

Students with vision loss and hearing loss have inclusionary needs that differ from those of students with other impairing conditions. Only by addressing the individual and unique needs of students who are blind or visually impaired, through cooperation and collaboration of the team members who are responsible for a student's program, can there be successful outcomes. Team members include: school administrators, regular classroom teachers, special teachers, physical and occupational therapists, speech therapists, families, the student, and other persons who need to have information or training in working with the special needs that the student demonstrates.

How to ensure that a student in an inclusionary setting will reach his/her potential is dependent upon the degree of independence achieved and the academic and social outcomes realized. Seven fundamentals are interrelated in the process of educating a sensory impaired child in his/her regular "home" school. These are:

1) The student needs,

2) Understanding,

3) Collaboration,
4) Creativity,

5) Expectations,

6) Standards, and

7) Sensitivity.

If each of these areas is addressed through ongoing communication, and with professional respect and knowledge, the student will have the advantage of becoming a confident and independent contributing member of society with a valued self-worth.

\section{REVIEW OF LITERATURE}

1. The Definition of Blind Students

Defines blind students as a condition of the eyes that cannot be completely corrected by typical means such as eyeglasses, medicines, or surgery. Jerome C. Yanoff, author of The Classroom Teacher's Inclusion Handbook, defines blind students as impairment "...in which a person can read only with the assistance of magnifying aids and/or large print."

Blind students usually learn how to read and write more slowly than sighted students since much learning, concept development, and detailed discrimination is a function of sight. However, blind or vision-impaired students must learn by other sensory means; feeling, touching, smelling and listening. Anxiety about survival and safety needs cause shyness, lack of confidence, introversion, and moodiness because they cannot see and imitate others.

Individuals who are congenitally blind, or who are blinded as a function of injury or disease, learn to rely on audition to compensate for their lack of vision. Effective listening skills appropriate for spatial navigation require considerable time and effort for both the orientation and mobility trainer and the student. Orientation and Mobility training can also expose individuals to significant risks and hazards due to the multitude of physical variables present in real-world navigation activities, such as crossing a street (Chew, 1984). Through 
training, audition can provide a highly sensitive warning, alerting, and scanning system with which to maintain a constant awareness of physical activity in threedimensional space (Wenzel \& Fisher, 1990). Audition is also significant in the development of a sense of spatial orientation and distance, as well as obstacle detection and avoidance by the blind (Barsch, 1968; Berner \& Lindh, 1980; Cratty, 1971).

Orientation and mobility skills in blind children are slow to develop and require extensive training. Before blind individuals can be independently mobile they must first know how to identify their position in space, and establish their relationship to other significant objects around them. The formal acquisition of these skills are referred to as orientation and mobility (OM), which is defined as "the process of instructing individuals who are visually impaired to maximize the use of their remaining senses to move about safely within their environment"

In the provision of an inclusive program for a student with vision loss, understanding is multi-faceted. It encompasses the entire program being offered and is an ongoing foundation for its success. An understanding and knowledge of the eye condition, its impact on academic and nonacademic learning and daily tasks, is frequently not included in the information sharing. This knowledge is fundamental to the understanding of the child's needs. It is also important to know at what stage of the student's development the vision loss occurred. Understanding the parent's emotional response (as well as their child's) to the vision loss is needed by professional and nonprofessional staff alike. Are they able to work with an angry or depressed parent or student? Have they acquired the interpersonal and professional skills to work under stress and with the stress of the involved parties? Parents need to be reassured that most blind and visually impaired children grow up to be happy productive adults. Has the sixteen year old student known that s/he will not be able to get a driving license or has s/he just been told? Can the staff who work with him/her really be able to empathize and do they have the time to address it with the student? How will this affect the social life of a visually impaired adolescent? Many of these issues can be helped by an understanding and considerate teacher of the visually impaired and through the coordination of that teacher's services and those of a guidance counselor or social worker in the educational system. Providing the regular teaching staff with ongoing in services to increase this understanding is necessary to create an atmosphere and climate of support for the student.

\section{Audio books in leaning EFL}

Audio books are educational materials that blind learners can use in every situation and every time without being tied to any place or without other people's help. Audio books produced for blind learners can create an environment to provide, enrich, inform, guide and teach subjects fully by creating an environment to learn and also develop independent learning skill to solve problems and answer questions as well as discuss different course related topics. An audio book is simply a book produced in a format that is audible. Audio books started in the Spanish language and soon blossomed into a multi-linguistic media. Many individuals and corporations use them for many reasons.

The very first audio book was produced in 1975 as a collection of short stories. The author was David Sanchez Julio and the audio book was in Spanish. Since then, audio books have been used to teach children to read, as a method for the blind to have access to books, and as a learning format for everything from learning a foreign language, guitar lessons, motivational seminars, and cooking lessons. The self-help industry utilizes audio books to tape workshops, conferences and basically uses them as a learning tool. 
Audio books have become so popular as a learning tool, because of the portability and relative low cost. In this fast-paced society, audio books have allowed us to multi-task while reading a book or learning a new skill. The ability to hear how words are pronounced can make all the difference when it comes to learning a language successfully.

Audio books have features that are valuable when learning a new skill. A feature such as the ability to replay a segment to reinforce what has been said. Another would be having the ability to listen to an unabridged version (word for word readings from a book), while following along in the actual hardcopy of the same book. Audio books make note taking easy, because of the ability to replay a section, as many times as necessary in order to get all the notes you need.

Audio books can be in CD, cassette or downloadable format. Giving a choice of formats allows the consumer to hear a book in the format best suited to their lifestyle. Audio books are very versatile so they fit just about anyone's need. Audio books are downloadable to your computer or MP3 player, or you can burn them to CDs. You can purchase them in bookstores or borrow them from your local library. You can find free audio books on numerous Websites or buy them from Audio book clubs. Audio books can be found alongside video rentals as consumers find they complement each other and are likely to buy them at the same time.

Parents have found that taking audio books along on long commutes can entertain the little ones and allow everyone to have a more peaceful drive. Many workers make good use of the daily commute by listening to self-improvement audio books, or pop in a audio book to catch up on their reading or to learn a language. Now the drive to and from work can be a productive time.

An audio book is a soundtrack that is for the most part a verbal speech. It is generally found on business printed material. It is not essentially a precise audio translation of a book. Although good numbers of books are created with an audio version for people who prefer it in that manner and for the blind people as well.

During the time of 1931, the legislative body instituted the talking book agenda, which was designed to be of assistance to the blind people who are not capable of reading print or texts. This agenda was recognized as the Book for the Adult Blind Project. The American Foundation for the Blind generated the very first talking books or the audio books during the year of 1932 .

A lot of people find these books very useful most especially the blind population. There are a lot of benefits in making use of an audio recorded book. Some of these benefits are:

Audio recorded books are very affordable. A lot of audio book organizations offer audio book download and rental services at a very small fee. For instance, there are a lot of downloadable audio books available only for a small fee of ten dollars or rent these audio recorded books without limit for a small fee of fifteen dollars. In addition to that there will be no cost for shipping these audio recordings.

With the use of an audio recording a person whether blind or not will be able to learn a lot of things. This is a very good education device. A person will be able to develop his or her listening skills by means of listening to audio recorded books. The listening skill is very important for the blind community, this would be one of the ways that they would be able to respond to their surroundings.

A blind person can make use of an audio recorded book without the help of Braille. A Braille scheme is a technique that is generally made use of by blind citizens to be able to read and write.

The audio books have grown into a billion dollar industry because of their 
portability, and use as a learning tool and ability to make reading fun. The audio book appeals to all ages and every family member from the youngest who needs to learn to read, a convenient way for mom to keep up with her book club members, a cool way for a teenager to "hear" his English assignment or dad to motivate himself before a big power meeting.

The benefits of audio books in distance education provide an easy access, low cost and swift alteration of the content when it is necessary. Since audio books are educational tools to support learning, distance programs must be established with simple vocabulary, supported with music and sound effects while the length of program, should ideally last between 45-60 minutes. Additionally, blind students need to listen to audiocassettes, CDs, MP3 players, etc. and enjoy the experience of being heard on audio book.

Audio books are not so widespread but the inexpensive cost and their potential in open education contexts is easily overlooked. In subject disciplines such as music, where sound is important for blind students, the use of an audio book as an educational medium is already well developed. In multimedia packages, sound and images are often combined to with good effect, yet audio book can sometimes play a similar role at much less cost. The use of audio books to support distance education can be extended to most disciplines. The following suggestions may help support diverse learners by putting audio books in good use (Race 1998: 99101):

1. Have good reasons for using audiobooks

2. Most learners have access to audiobooks

3. Label audio-books informatively

4. Keep audio-book extracts short and sharp

5. Use audio-books where the tone of voice is important
6. Sound can help open education learners about the subject-related jargon

7. Use audio-books to bring open education to life

8. Clarify exactly when a recorded episode must be used

9. Turn open education learners' listening into an active process

10. When using audio-book to help your learners achieve particular outcomes, explain exactly what they must be getting out of listening to the tape

11. Consider using audio-book to give open learners feedback on their tutormarked assignments.

\section{METHODOLOGY}

This research conducted used preexperimental design with one group of pre-test and posttest. The study was conducted at SLB YAPTI Makassar with a number of samples taken were 20 students conducted randomly. The instruments in this study were tests, observations, and questionnaires. In data analysis the writer using SPSS 21 to analyze the data.

\section{FINDINGS}

1. Findings

1.1 The Implementation of Audio Books as Teaching Media for Blind Students in Learning English

Blind students usually learn how to read and write more slowly than sighted students since much learning, concept development, and detailed discrimination is a function of sight. However, blind or vision-impaired students must learn by other sensory means; feeling, touching, smelling and listening.

Individuals who are congenitally blind, or who are blinded as a function of injury or disease, learn to on audition to compensate for their lack of vision. Effective listening skills appropriate for spatial navigation require considerable time and effort for both the orientation and mobility trainer and the student. 
Teachers' lack of knowledge of appropriate teaching methodologies and techniques, their lack of enthusiasm, and an emphasis on learning content rather than processes negatively impact blind students' literacy development. There is an overuse of lecturing and rote memorization, so that instruction tends to be repetitive and boring. The traditional way of teaching Braille, starting with listening before writing.

Good listeners are good catchers because they give their speakers a target and then move that target to capture the information that is being sent. When good listeners don't understand their speakers, they will send signals to the speaker about what they expect next, or how the speaker can change the speed of information delivery to suit the listener. Above all, a good listener involves all of their face to be an active moving listener.

Audio books are educational materials that blind learners can use in every situation and every time without being tied to any place or without other people's help. Audio books produced for blind learners can create an environment to provide, enrich, inform, guide and teach subjects fully by creating an environment to learn and also develop independent learning skill to solve problems and answer questions as well as discuss different course related topics. An audio book is simply a book produced in a format that is audible.

An audio book is a soundtrack that is for the most part a verbal speech. It is generally found on business printed material. It is not essentially a precise audio translation of a book. Although good numbers of books are created with an audio version for people who prefer it in that manner and for the blind people as well.

A blind person can make use of an audio recorded book without the help of Braille. A Braille scheme is a technique that is generally made for use by blind citizens to be able to read and write.
The benefits of audio books in distance education provide an easy access, low cost and swift alteration of the content when it is necessary. Since audio books are educational tools to support learning, distance programs must be established with simple vocabulary, supported with music and sound effects while the length of program, should ideally last between 45-60 minutes. Additionally, blind students need to listen to audiocassettes, CDs, MP3 players, etc. and enjoy the experience of being heard on audio book.

Referring to explanation above, the writer wants to know the ability of the SLB YAPTI Makassar in learning English especially in listening so the writer gives test. The result of the test can be showed below:

Table 1 The Percentage of Students' Pretest Score

\begin{tabular}{llcc}
\hline Classification & Score & \multicolumn{2}{c}{ Experimental Group } \\
\cline { 3 - 4 } & & Frequency & Percentage \\
Very Good & $81-100$ & 0 & 0 \\
Good & $61-80$ & 1 & 5 \\
Fair & $41-60$ & 17 & 85 \\
Poor & $21-40$ & 2 & 10 \\
Very Poor & $1-20$ & 0 & 0 \\
Total & & 20 & 100 \\
\hline
\end{tabular}

From the classification, the scores, and the rate percentage of the pre-test illustrated in the table above that out of 20 students, one of the bottom categories very poor was not employed by anyone of them. There were 1 (5\%) students named as good. In this group, there were $17(85 \%)$ students have the ability to gain the Fair level and there were $2(10 \%)$ students have the ability to gain the poor level.

Table 2 The Percentage of Students' Posttest Score

\begin{tabular}{llcc}
\hline Classification & Score & \multicolumn{2}{c}{ Experimental Group } \\
\cline { 3 - 4 } & & Frequency & Percentage \\
Very Good & $81-100$ & 0 & 0 \\
Good & $61-80$ & 7 & 35 \\
Fair & $41-60$ & 13 & 65 \\
Poor & $21-40$ & 0 & 0 \\
\hline
\end{tabular}




\begin{tabular}{llll}
\hline Very Poor & $1-20$ & 0 & 0 \\
Total & & 20 & 100 \\
\hline
\end{tabular}

From the classification, the scores, and the rate percentage of the post-test illustrated in the table above that out of 20 students, two of the bottom categories poor and very poor were not employed by anyone of them. There were $13(65 \%)$ students named as fair. In this group, there were $7(23 \%)$ students have the ability to gain the good level.

Table 3 The Mean Score and Standard Deviation of Students' Pretest and Post Test

\begin{tabular}{lcl}
\hline Group & $\begin{array}{l}\text { Mean } \\
\text { Score }\end{array}$ & $\begin{array}{l}\text { Standard } \\
\text { Deviation }\end{array}$ \\
\hline Pre-test & 53.75 & 7.412 \\
Post-test & 64.00 & 6.996 \\
\hline
\end{tabular}

It can be observed in the table above that the pre-test was valued 53.75 for its mean score with the standard deviation obtained 7.412. For the post-test, the mean score was 64.00 with the standard deviation valued at 6.996. It can be referred from the description about the mean score and the standard deviation for both pretest and posttest that has a little improvement in enriching the English Students Ability in Learning EFL from the mean score 53.75 in pretest to 64.00 in posttest, but the level of the six category is still in good level.

Table 4 The Paired t-test Value of Students'

\begin{tabular}{lccc}
\hline Variables Probability & $\boldsymbol{\alpha}$ & Remarks \\
& Value & & \\
\hline $\begin{array}{l}\text { Pretest } \\
\text { and }\end{array}$ & 0,00 & 0,05 & Significant \\
Posttest & & & \\
\hline
\end{tabular}

Based on the result of data analysis as summarized in table 4 pretest and posttest, the researcher found that the $\mathrm{p}$-Value (probability value) is higher than $\alpha(0.000>$ 0.05 ) and the degree of freedom 19. The ttest value of was remarked significantly different. It indicated that the alternative hypothesis $\left(\mathrm{H}_{1}\right)$ was accepted and, of course, the null hypothesis $\left(\mathrm{H}_{0}\right)$ was rejected. It showed that the use of audio books not significantly enrich English students' ability in learning EFL.

\subsection{Audio Books in Leaning EFL}

As educators know, there are three ways all students learn — visually, auditorially, and kinesthetically. Most blind students learn by both auditory and kinesthetic means. These students also on all of their past experiences to make a connection with new materials and often us, as educators, are responsible for building that experience base to assist these blind/visually impaired students develop a broader repertoire from which to draw from when learning. Never assume a blind/visually- impaired students has experience with anything related to space. It can't be touched. We must provide intricate verbal details and hands-on activities to make this all possible

To organize an appropriate program for teaching to students who are blind, a complete cycle of the curriculum development process must be developed.

Curriculum studies is a field that addresses distinct and important issues related to education. These issues tend to transcend the various areas of educational inquiry as they impact upon the design, implementation, and evaluation of educational programs. We can see in tables of following about the material must appropriate with curriculum :

Table 5 The Material is Appropriate with Curriculum

\begin{tabular}{lcrc}
\hline No & $\begin{array}{l}\text { Answer } \\
\text { Category }\end{array}$ & Frequency & Percentage \\
1 & Yes & 15 & $75 \%$ \\
2 & Mavbe & 3 & $15 \%$ \\
3 & No & 2 & $10 \%$ \\
& Total & 20 & $100 \%$ \\
\hline
\end{tabular}

From the table uses above indicates that 15 respondents or $75 \%$ said the material is appropriate with curriculum, 3 respondents 
or $15 \%$ said maybe, and 2 students or $10 \%$ said the material isn't appropriate with curriculum.

A blind person can make use of an audio recorded book without the help of Braille. A Braille scheme is a technique that is generally made for use by blind citizens to be able to read and write.

The benefits of audio books in distance education provide an easy access, low cost and swift alteration of the content when it is necessary. Since audio books are educational tools to support learning, distance programs must be established with simple vocabulary, supported with music and sound effects while the length of program, should ideally last between 45-60 minutes. Additionally, blind students need to listen to audiocassettes, CDs, MP3 players, etc. and enjoy the experience of being heard on audio book. To know more about that we can see in the table below :

Table 6 The Benefits of Audio Book in English Learning

\begin{tabular}{clcc}
\hline No & Answer Category & Frequency & Percentag \\
1 & Many & 16 & $80 \%$ \\
2 & Few & 3 & $15 \%$ \\
3 & Nothing & 1 & $5 \%$ \\
& Total & 20 & $100 \%$ \\
\hline
\end{tabular}

From the table above indicate that 16 respondents or $80 \%$ said there are many benefits of audio book in English learning, 3 respondents or $15 \%$ said few, and 1 student or $5 \%$ said there aren't Benefits of Audio Book in English Learning.

A lot of people find these books very useful most especially the blind population. There are a lot of benefits in making use of an audio recorded book. Some of these benefits are audio recorded books are very affordable. A lot of audio book organizations offer audio book download and rental services at a very small fee. For instance, there are a lot of downloadable audio books available only for a small fee of ten dollars or rent these audio recorded books without limit for a small fee of fifteen dollars. In addition to that there will be no cost for shipping these audio recordings.

With the use of an audio recording a person whether blind or not will be able to learn a lot of things. This is a very good education device.

\section{Discussion}

The discussion section deals with the interpretation of test result both pretest and posttest and description of data gained from the questionnaire which is presented based on the student's interest of the use of brain writing learning model using episodic memory in teaching narrative text.

The result of students' pretest, the researcher assumed that the prior knowledge of the students seem lack because the students did not have any knowledge about the test or they are not given the treatment yet by using the method. There are some factors that can influence students' achievement. Slameto (1988) states that factors that influence teaching and learning process can be divided into two parts namely: internal factor and external factor. External factors consist of school factor, teaching procedure, school physical condition, curriculum, school discipline, teaching media, time schedule, and peer group. While internal factors are motivation, physical condition, students interest, student intelligence, attitude, language aptitude, and concentration. Another factor that can influence students' achievement in pretest that is teaching media and students' attitude. Therefore, pretest was given to find out prior knowledge of students, so the researcher should treat the students by using memorization as one technique to overcome the low mastery of students.

The statistical data based on the t-test through SPSS Version 21 to test the hypothesis indicated that the probability value of the experimental group is higher than alpha $(\alpha)$ in which $(0.000<0.05)$. It 
meant that the $\mathrm{H}_{1}$ of the hypothesis was accepted.

The questionnaire was given to the students to cover the statements about the use of audio books in learning EFL. From 20 students, 15 respondents or $75 \%$ said the material is appropriate with curriculum, 3 respondents or $15 \%$ said maybe, and 2 students or $10 \%$ said the material isn't appropriate with curriculum. So, we can conclude that audio books was based on the curriculum.

And From, 20 students, 16 respondents or $80 \%$ said there are many benefits of audio book in English learning, 3 respondents or $15 \%$ said few, and 1 student or $5 \%$ said there aren't benefits of audio book in english learning. Based on the result, we can conclude that audio book very beneficial to blind students in SLB YAPTI Makassar

The result of questionnaire that was given after the posttest shows that the audio books appropriate with the curriculum in school and also audio book very beneficial to blind students in SLB YAPTI Makassar.

\section{CONCLUSION}

The results of the study show that the implementation of audio books as teaching media for blind students in learning English can help students in the learning process. The implementation of the audio book also increases student motivation in learning because it makes it easier for students to study anywhere and anytime

\section{REFERENCE}

Arter, C. (1997). English. In H. Mason and S. McCall, (Eds). Visual Impairment: Access to education for children and young people. London: David Fulton.

Blake, S.J.(2003), The Importance of Braille Literacy.http://blindness, growingstro ng.org/ed/aa010101a.htm

Fakultas Keguruan dan Ilmu Pendidikan Universitas Bosowa Makassar
BOGDAN, R., \& BIKLEN, S. K. (1998). Qualitative Research for Education: An Inroduction to Theory and Methods. Boston: Allyn and Bacon.

Halten, P. (1997). The core curriculum for blind and visually impaired students including those with additional disabilities. ANZAEVH Conference Proceedings: Staying ahead in changing times. Adelaide: InPrint.

Ianuzzi, J.W. (1999). Braille Literacy in America: A student's view. Online: Available from Other Visions e-zine.

Gay , L.R.. (1981). Education Research. Michigan. An Arbor.

OZGUR, A.Z. (1999). "Radio as a medium supports learning at distance learning and open education faculty applications." BITE. Ankara: Ministry of Education, FRTEB.

Ryles, R. (1996). The impact of Braille reading skills on employment, income, education and reading habits. Journal of Visual Impairment and Blindness, 90 (3).

Rowntree, D. (1994). Teaching with Audio in Open and Distance Education. London, Kogan Page

Schmeilder, E. \& Kirchner, C. (2001). Adding audio description: Does it make a difference? Journal of Visual Impairment and Blindness, 95(4), 197-213.

Snow. (2010). Students Who are Blind or Who Have Limited Vision. University of Toronto.

Suharsini. 1996. Prosedur Penelitian. Jakarta . Rieneka Cipta.

Sutrisno, Hadi. 1994. Metodologi Reseach Jilid ,I dan II Cet.XIV; Jogjakarta: UGM

Wittenstein, S.H, \& Pardee, M.L., (1996). Teachers voices: Comments on Braille and literacy from the field. Journal of Visual Impairment and Blindness. 90 (3): 201-209 